\title{
Metal Ammonium Phosphates Ion Exchangers for the Remediation of Low-Level Nuclear Wastes
}

\author{
Alistair F. Holdsworth, ${ }^{1,2} *$ Harry Eccles, ${ }^{1} *$ and Gary Bond ${ }^{1}$
}

1) Research Centre for Smart Materials, Faculty of Science \& Technology, University of Central Lancashire, Fylde Road, Preston, United Kingdom, PR1 2HE.

2) Now at the School of Chemical Engineering \& Analytical Science, University of Manchester, Oxford Road, Manchester, United Kingdom, UK, M13 9PL.

* Corresponding Authors: Alistair.Holdsworth@manchester.ac.uk; HEccles@uclan.ac.uk

Abstract: The nuclear industry generates large volumes of liquid wastes during decommissioning and decontamination activities which require extensive clean-up for recycle and/or disposal. The disposal of spent ion exchange materials used to clean these decontamination liquors is challenging and costly for the nuclear industry due to problematic end-of-life handling and low capacities of these materials for most radionuclides. Certain mixed-metal phosphates could be advantageous in this role due to their inherent vitrification properties and potentially high capacities for cationic and/or anionic radionuclides. Similar ammonium-based ion exchangers like the caesium-selective ammonium phosphomolybdate (AMP) are well known in the nuclear industry, but outside of this, such materials remain largely unexplored for this purpose. In this publication, we assess several metal ammonium phosphates (MAPs) and related compounds prepared using a continuous flow technique for their ability to act as ion exchangers for the remediation of surrogate radionuclides from a model decontamination solution, and discuss their possible implementation for the cleanup of low-level nuclear wastes.

Keywords: ion exchange, nuclear waste, remediation, decontamination, decommissioning, ammonium phosphates, metal phosphates, metal ammonium phosphates, ammonium metal phosphates, surrogate radionuclides.

\section{1: Introduction}

Decommissioning and decontamination are integral to the nuclear fuel cycle. Over the next few decades, these will increase significantly as many reactors and associated facilities reach the end of their useful lives. ${ }^{1}$ Decontamination processes during decommissioning operations serves as a means of re-categorising nuclear wastes to lower levels, reducing disposal costs. ${ }^{2,3}$ Surfaces are typically decontaminated with large volumes of various aqueous solutions which are become contaminated with radionuclides, ${ }^{2,3}$ amongst other reagents. ${ }^{4}$ Concentration of the dilute radioactive species in these liquid wastes onto a much smaller volume of solid adsorbent allows for recycling. Regardless of nature, these adsorbents then require disposal, a factor which remains a challenge to this day. ${ }^{2,3}$ In this publication, we undertake an initial assessment of several inorganic mixed-metal phosphate adsorbents with potentially high capacities for radionuclides in the remediation of such decontamination solutions and with a promising end-of-life disposal strategy to address these challenges.

Struvite- $\mathrm{K}\left(\mathrm{KMgPO}_{4} \cdot 6 \mathrm{H}_{2} \mathrm{O}\right)$ and some calcium phosphates can sequester $\mathrm{Cs}^{+}$from aqueous solutions, ${ }^{5,6}$ forming stable, insoluble ceramics upon calcination, ${ }^{7}$ though to our knowledge this has never been extended to other target ions. Compounds of the form $\mathrm{AMPO}_{4}$ are readily prepared at scale from low-cost reagents, ${ }^{8-11}$ have very high theoretical capacities $\left(856 \mathrm{mg} / \mathrm{g} \mathrm{Cs}^{+}\right.$uptake on MgAP, summarised in Table 1) and similar systems have demonstrable vitrification properties for disposal. ${ }^{2,12-14}$ This facile preparation contrasts with zirconium, titanium and titanyl phosphates $\left(\mathrm{M}\left(\mathrm{HPO}_{4}\right)_{2}\right.$ or $\mathrm{NH}_{4} \mathrm{TiOPO}_{4}$ ), well-known layered adsorbents normally prepared using inefficient batch hydrothermal methods. ${ }^{15,16}$ The wellcharacterised ammonium phosphomolybdate (AMP), a highlyselective adsorber of $\mathrm{Cs}^{+}$ions from acidic solutions, is believed to function by ion exchange using $\mathrm{NH}_{4}{ }^{+}$ions, though $\mathrm{H}^{+}$exchange has been reported for other phosphate adsorbents. ${ }^{15}$ Several of our previous publications have explored the use of AMP for, heterogeneous isolation of $\mathrm{Cs}^{+}$in reprocessing flowsheets, granting a direct recovery and disposal route to this energetic fission product, which could mitigate many of the challenges within the recycling of spent fuel. ${ }^{17-20}$ For decontamination purposes however, selectivity is unnecessary, rather an ability to absorb a wide range of radionuclide contaminants is often preferred. ${ }^{21}$

We previously demonstrated ${ }^{22}$ an efficient, scalable continuous flow synthesis method ${ }^{23}$ for the quantitative preparation of metal ammonium phosphates (MAPs) and related compounds with a small particle sizes $(<24 \mu \mathrm{m})$, narrow size distributions, and high surface areas (up to $50 \mathrm{~m}^{2} / \mathrm{g}$, see Table 1 ). This publication presents a cursory investigation into the potential of six MAPs (MgAP, MnAP, FeAP, CoAP, NiAP, ZnAP) and one hydrogen phosphate (SnHP) in adsorbing five ions from a model spent decontamination liquor: $\mathrm{Cs}^{+}$, $\mathrm{Sr}^{2+}, \mathrm{Zr}^{4+}, \mathrm{Ce}^{4+}$ and $\mathrm{MoO}_{4}{ }^{2-}$. Here, $\mathrm{Ce}$ is present as a surrogate for $\mathrm{U}$ and other polyvalent ions that may be present in such liquors. ${ }^{21}$

\section{2: Experimental}

\subsection{Materials}

The adsorbents (MgAP, MnAP, FeAP, CoAP, NiAP, ZnAP, and SnHP) were synthesised and characterised as described previously. ${ }^{22}$ All powders were dried overnight at $80{ }^{\circ} \mathrm{C}$ before testing. Analar grade caesium nitrate, strontium nitrate, ceric ammonium nitrate, zirconyl nitrate, sodium molybdate, and nitric acid were acquired from Fisher Scientific or Sigma-Aldrich and used as procured. Deionised water (> $18 \mathrm{M} \Omega / \mathrm{cm}$ ) was used for all experiments. The model decontamination liquor was made from $1000 \mathrm{ppm}$ stock solutions of $\mathrm{Cs}^{+}, \mathrm{Sr}^{2+}, \mathrm{Zr}^{4}, \mathrm{Ce}^{4+}$ and $\mathrm{MoO}_{4}{ }^{2-}$. The molybdate stock solution was acidified to $\mathrm{pH} 6$ with nitric acid before use to convert to the protonated form. The model solution contained $4 \mathrm{ppm} \mathrm{Cs}^{+}$and $\mathrm{Zr}^{4+}$, $2.7 \mathrm{ppm} \mathrm{Sr}^{2+}$ and $\mathrm{Mo}$ (as $\mathrm{MoO}_{4}{ }^{2-}, 2.7 \mathrm{ppm} \mathrm{Mo}$ ) and $49 \mathrm{ppm} \mathrm{Ce}{ }^{4+}$, with a recorded $\mathrm{pH}$ of 3.3 .

\subsection{Batch and Time-Dependent Adsorption Studies}

Batch adsorption studies were conducted using $50 \mathrm{ml}$ of the model liquor and $0.25 \mathrm{~g}$ of adsorbent. Samples were agitated at $180 \mathrm{rpm}$ (Julabo SW ZZ) at $25{ }^{\circ} \mathrm{C}$ with an aliquot taken after $24 \mathrm{~h}$. These were diluted with $1 \%$ nitric acid and analysed using ICP-OES (ThermoScientific ICAP 7000) and ICP-MS (Thermo-Electron X-Series) for 
metals content to determine uptake, with appropriate multistandard calibrations performed before analysis. The $\mathrm{pH}$ of the test solution was measured pre- and post-equilibration. Duplicate results were within experimental error (t/- 2\%). Time-dependent adsorptions to determine rates of uptake were analysed in the same manner with aliquots taken after $0.5,1$, and $2 \mathrm{~h}$. Distribution coefficients ( $k_{d}$ values, in $\mathrm{ml} / \mathrm{g}$ ) were calculated according to Equation 1, where $C_{0}$ and $C_{e}$ are the initial and equilibrium liquor concentrations respectively, $\mathrm{V}$ is the volume of liquor $(\mathrm{ml})$, and $\mathrm{m}$ is the mass of adsorbent $(\mathrm{g})$ utilised in the experiment.

$$
k_{d}=\left(C_{0}-C_{e}\right) / C_{e} \cdot V / m
$$

\section{3: Results and Discussion}

\section{1: General Observations and Proposed Mechanisms of Action}

The seven adsorbents were exposed to the model liquor containing the five metals for $24 \mathrm{~h}$ with aliquots taken after this period to determine adsorption and/or ion exchange performance. The initial, slightly acidic $\mathrm{pH}$ of the model liquor (3.3), results from the partial hydrolysis of the small, highly charged ions present. ${ }^{24} \mathrm{The} \mathrm{pH}$ of the model liquor increases to a neutral equilibrium value of between 7 and 8 within 5 minutes of the addition of the MAP adsorbents and maintains this throughout the duration of exposure, though the slightly acidic conditions are maintained with SnHP.

\begin{tabular}{llllllllll}
\hline MAP & Formula & MW & \multicolumn{3}{c}{ Theoretical capacity $(\mathrm{mg} / \mathrm{g})$} & & \multicolumn{2}{l}{ BET } & PSD \\
\hline & & $\mathrm{g} / \mathrm{mol}$ & $\mathrm{Sr}^{2+}$ & $\mathrm{Zr}^{4+}$ & $\mathrm{Mo}^{\mathrm{Vl}}$ & $\mathrm{Cs}$ & $\mathrm{Ce}$ & $\left(\mathrm{m}^{2} / \mathrm{g}\right)$ & $(\mu \mathrm{m})$ \\
$\mathrm{MgAP}$ & $\mathrm{MgNH}_{4} \mathrm{PO}_{4} \cdot \mathrm{H}_{2} \mathrm{O}$ & 155.33 & 282 & 147 & 309 & 856 & 226 & 15.7 & 13.6 \\
MnAP & $\mathrm{MnNH}_{4} \mathrm{PO}_{4} \cdot \mathrm{H}_{2} \mathrm{O}$ & 185.96 & 236 & 123 & 258 & 715 & 188 & 4.6 & 22.8 \\
FeAP & $\mathrm{FeNH}_{4} \mathrm{PO}_{4} \cdot \mathrm{H}_{2} \mathrm{O}$ & 186.87 & 234 & 122 & 257 & 711 & 187 & 49.8 & 9.5 \\
CoAP & $\mathrm{CoNH}_{4} \mathrm{PO}_{4} \cdot \mathrm{H}_{2} \mathrm{O}$ & 189.96 & 231 & 120 & 253 & 700 & 184 & 6.5 & 23.5 \\
NiAP & $\mathrm{NiNH}_{4} \mathrm{PO}_{4} \cdot 6 \mathrm{H}_{2} \mathrm{O}$ & 279.79 & 157 & 82 & 171 & 475 & 125 & 9.5 & 7.7 \\
ZnAP & $\mathrm{ZnNH}_{4} \mathrm{PO}_{4}$ & 178.41 & 246 & 128 & 269 & 745 & 196 & 3.6 & 9.7 \\
SnHP & $\mathrm{SnHPO}_{4}$ & 214.69 & 204 & 106 & 223 & 619 & 163 & 4.7 & 6.5 \\
\hline
\end{tabular}

Table 1: Theoretical capacities of the candidate adsorbents (accounting for MW and the above stoichiometry), alongside BET surface areas and particle sizes previously reported. ${ }^{22}$

The adsorption of the cations from the model liquor onto the tested adsorbents are believed to occur via exchange with ammonium ions as for AMP, ${ }^{17-20}$ with the exception of SnHP, where $\mathrm{H}^{+}$ions are exchanged instead. The behaviour of molybdate $\left(\mathrm{MoO}_{4}{ }^{2-}\right)$ may lie more in adsorption rather than true ion exchange, ${ }^{25}$ but the chemical nature of these interactions is beyond the scope of this initial study. The exchange of the higher valence ions is, in theory, more favourable entropically (Equations 2-4) ${ }^{26}$ as driven by the displacement of greater numbers of ammonium ions and both inner and outer sphere waters of hydration, and likely energetically via binding of oxophilic ions such as $\mathrm{Zr}^{4+}$ with phosphate. Additionally, the theoretical capacities for the polyvalent ions are lower, ${ }^{26}$ although hydrolysis reduces the effective charge which can affect otherwise unlikely adsorption process. ${ }^{21,27-29}$ Table 1 summarises the theoretical capacities of the seven candidate adsorbents alongside some previously recorded physiochemical properties. ${ }^{22}$

$$
\begin{aligned}
& \mathrm{Cs}^{+}{ }_{\text {(aq) }}+\mathrm{NH}_{4} \mathrm{MPO}_{4(\mathrm{~s})} \rightarrow \mathrm{CsMPO}_{4(\mathrm{~s})}+\mathrm{NH}_{4}^{+}{ }_{\text {(aq) }} \\
& \mathrm{Sr}^{2+}{ }_{(\mathrm{aq})}+2 \mathrm{NH}_{4} \mathrm{MPO}_{4(\mathrm{~s})} \rightarrow \mathrm{Sr}\left(\mathrm{MPO}_{4}\right)_{2(\mathrm{~s})}+2 \mathrm{NH}_{4}^{+}{ }_{\text {(aq) }} \\
& \mathrm{Zr} / \mathrm{Ce}_{(\text {(aq) }}^{4+}+4 \mathrm{NH}_{4} \mathrm{MPO}_{4(\mathrm{~s})} \rightarrow \mathrm{Zr} / \mathrm{Ce}\left(\mathrm{MPO}_{4}\right)_{4(\mathrm{~s})}+4 \mathrm{NH}_{4}^{+}{ }_{(\mathrm{aq})}
\end{aligned}
$$

\section{2: Batch Adsorptions}

The $24 \mathrm{~h}$ distribution coefficients of the five ions in the model liquor onto our seven adsorbent compounds are presented graphically in Figure 1. The highest $\mathrm{k}_{d}$ values after $24 \mathrm{~h}$ were observed for $\mathrm{Ce}^{4+}$ and $\mathrm{Zr}^{4+}$, followed by $\mathrm{Sr}^{2+}$, and finally $\mathrm{Cs}^{+}$. This demonstrates a decreasing trend in the affinity of each target ion for our adsorbents with decreasing charge density. The behaviour of $\mathrm{Mo}^{\mathrm{VI}}$ is intermediate, likely due to the variable and different chemistry between this species and the other metals tested.

FeAP shows poor adsorption of $\mathrm{Zr}, \mathrm{Mo}$ and $\mathrm{Cs}$ from the model liquor. This corresponded with a colour change from the initial dark green of the starting material to off-white after $24 \mathrm{~h}$. This likely results from the oxidation of $\mathrm{Fe}^{2+}$ to $\mathrm{Fe}^{3+}$, forming ferric phosphate. The observed adsorption of $\mathrm{Sr}^{2+}$ and $\mathrm{Cs}^{+}$possibly arise from formation of mixed-metal phosphates, ${ }^{6}$ though further analysis would be required to confirm this. The performance of FeAP before oxidation remains unquantified.

Both MgAP and NiAP can interconvert between mono- and hexahydrated derivatives via hydrolysis and dehydration respectively, as per Equation 5, with speciation of these two compounds dependent on temperature, concentration, and a multitude of other factors. ${ }^{30,31}$ The $24 \mathrm{~h}$ adsorptions of $\mathrm{Sr}^{2+}, \mathrm{Zr}^{4+}$ and $\mathrm{Mo}^{\mathrm{V}}$ onto MgAP and NiAP are similar, although the MgAP affinities for $\mathrm{CS}^{+}$and $\mathrm{Ce}^{4+}$ are higher.

$$
\mathrm{MgNH}_{4} \mathrm{PO}_{4} \cdot \mathrm{H}_{2} \mathrm{O}_{(\mathrm{s})}+5 \mathrm{H}_{2} \mathrm{O}_{(\mathrm{l})} \leftarrow \rightarrow \mathrm{MgNH}_{4} \mathrm{PO}_{4} \cdot 6 \mathrm{H}_{2} \mathrm{O}_{(\mathrm{s})}
$$

As previously stated, we believe SnHP functions via exchange of $\mathrm{H}^{+}$ ions instead of $\mathrm{NH}_{4}{ }^{+}$as for the MAPs, meaning the lower $\mathrm{pH}$ of the model liquor is maintained after $24 \mathrm{~h}$. This likely explains the observed increase in $\mathrm{Mo}^{\mathrm{Vl}}$ absorption after $24 \mathrm{~h}$, alongside the increased $\mathrm{Zr}^{4+}$ affinity. 


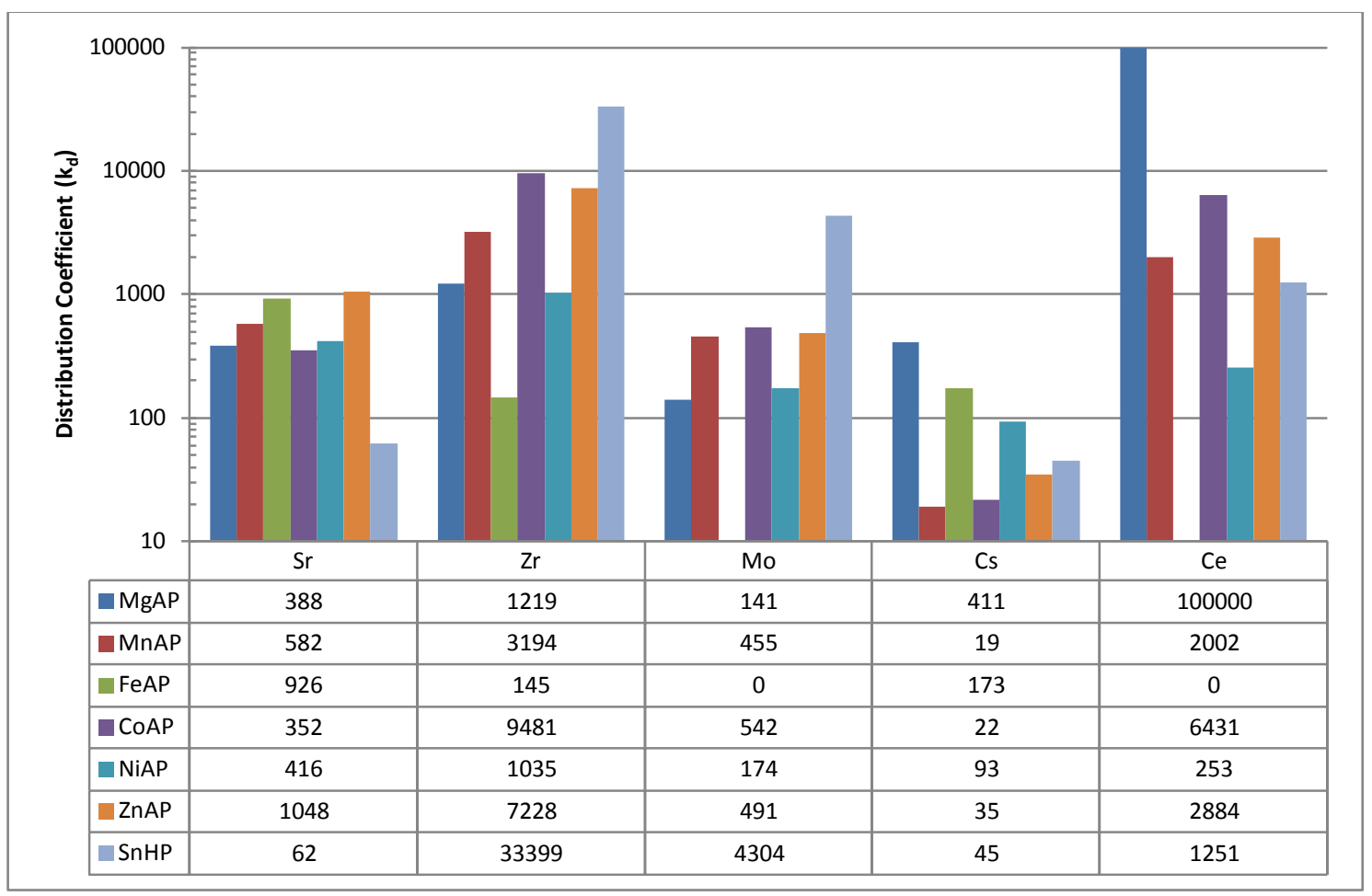

Figure 1: Distribution coefficients of the five elements in the model liquor on the seven tested adsorbents after $24 \mathrm{~h}$. The MgAP uptake of Ce (100\%) was given an arbitrary value of 100000 for graphical purposes.

\section{3: Rate of Adsorption}

In order to assess the rate of metal ion adsorption from the model liquor onto our adsorbents, ZnAP was selected for further study, with aliquots taken after 30 mins, 1 hour, and 2 hours of exposure and analysed in the same manner as the batch experiments above. This data is presented in Figure $\mathbf{2}$ below, expressed as percentage of each metal ion adsorbed, demonstrating that adsorption is rapid, attaining high levels within 30 minutes of exposure, though some equilibration occurs beyond this time. ${ }^{21,32}$ This suggests that the kinetics of adsorption or exchange for this class of compound are rapid for most of the cations in the model liquor, with the exception of $\mathrm{Cs}^{+}$and $\mathrm{Sr}^{2+}$.

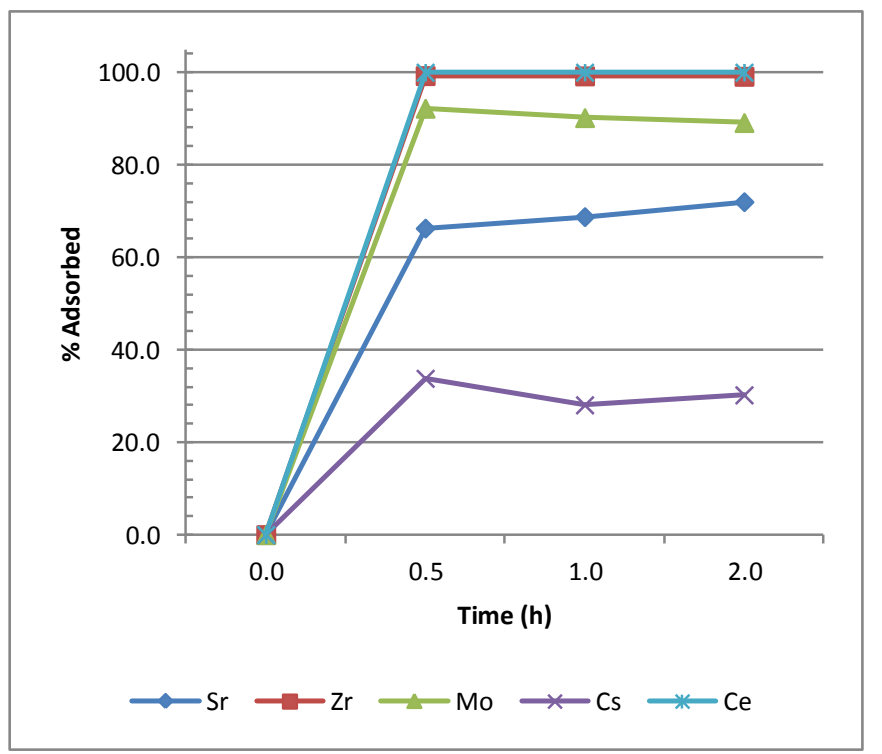

Figure 2: Variation in adsorption (as \% of total metal ion on solid) from model liquor onto ZnAP with time.

\section{4: Discussion and Conclusion}

The results presented have demonstrated the efficacy of some MAPs and related compounds to chemically adsorb several problematic species from a model decontamination liquor containing five such elements in varying concentrations. This work was conducted as an initial screening study to identify the most promising candidate(s) for further study, and as such only the multi-element solution was analysed, rather than separate single-ion uptake measurements.

As stated in the introduction, these materials are of interest as a potential immobilisation matrix for adsorbed radionuclides with the addition of an appropriate flux; MAPs decompose upon heating to form ceramic pyrophosphates, as per Equation $6,{ }^{31}$ which allows for formation of an insoluble glassy wasteform. ${ }^{13,14}$

$$
2 \mathrm{NH}_{4} \mathrm{MPO}_{4} \cdot \mathrm{nH}_{2} \mathrm{O}_{(\mathrm{s})} \rightarrow \mathrm{M}_{2} \mathrm{P}_{2} \mathrm{O}_{7(\mathrm{~s})}+2 \mathrm{NH}_{3(\mathrm{~g})}+(\mathrm{n}+1) \mathrm{H}_{2} \mathrm{O}_{(\mathrm{g})}
$$

We have presented promising uptakes of $\mathrm{Zr}$, Mo, and Ce from our model liquor by the majority of the candidate adsorbents tested, along with demonstrable rapid kinetics of adsorption as initial observations in the presented scoping study. Several variations in adsorbent chemistry can be attributed to several chemical factors $^{21,30-32}$ which will be explored further in subsequent publications.

\section{5: References}

1. $59^{\text {th }}$ IAEA General Conference, Nuclear Technology Review, 2015, GC(59)/INF/2, IAEA, Vienna, Austria, 2015.

2. Chemical Separation Technologies and Related Methods of Nuclear Waste Management: Applications, Problems and Research Needs. Choppin, G. R.; Khankhasayev, M. K., Eds.; Kluwer, Dordrecht, Netherlands, 1998.

3. The Nuclear Fuel Cycle: From Ore to Waste. Wilson, P. D.; Ed. Oxford University Press, Oxford, UK, 1996. 
4. O'Hanlon, J. A.; Chapman, R. D.; Taylor, F.; Denecke, M. A Quantification of common aminopolycarboxylic acids in trench leachate from the Low Level Waste Repository. J. Radioanal. Nucl. Chem., 2019, 322, 1915-1929. https://doi.org/10.1007/s10967019-06895-X

5. Dikiy, N. P.; et al. SORPTION PROPERTIES OF MAGNESIUMPOTASSIUM PHOSPHATE MATRIX Probs. Atom. Sci. Tech., 2015, 3, 97, 79-82.

6. Borai, E. H.; Attallah, M. F.; Shehata, F. A.; Hilal, M. A.; Abo-Aly, M. M. Removal of some Fission Products from Low Level Liquid Radioactive Waste by Chemical Precipitation. IAEA report: EG0800311, Vienna, Austria.

7. IAEA Tech. Report Series 436: Disposal Options for Disused Radioative Sources, IAEA, Austria, 2005.

8. Bassett, H.; Bedwell, W. L. Studies of Phosphates. Part I. Ammonium Magnesium Phosphate and Related Compounds. J. Chem. Soc., 1933, 854-871. https://doi.org/10.1039/JR9330000854

9. Holdsworth, A. F. Novel Metal Complex Fire Retardants for Engineering Polymers. PhD Thesis, University of Bolton, UK, 2015

10. Holdsworth, A. F.; Horrocks, A. R.; Kandola, B. K.; Price, D. The potential of metal oxalates as novel flame retardants and synergists for engineering polymers. Poly. Degrad. Stab., 2014, 110 , 290-297. https://doi.org/10.1016/i.polymdegradstab.2014.09.007

11. Holdsworth, A. F.; Horrocks, A. R.; Kandola, B. K. Synthesis and thermal analytical screening of metal complexes as potential novel fire retardants in polyamide 6.6. Poly. Degrad. Stab., 2017, 144, 420-433. https://doi.org/10.1016/j.polymdegradstab.2017.09.002

12. Ojovan, M. I.; Batyukhnova, O. G. Glasses for Nuclear Waste Immobilisation. WM'07 Conference, Tucson, Arizona, 2007.

13. Petitjean, V.; Fillet, C.; Boen, R.; Veyer, C.; Flament, T. Development of vitrification process and glass formulation for nuclear waste conditioning. WM'02 Conference, Tucson, Arizona, 2002.

14. Wagh, A. S.; Advances in Inorganic Phosphate Materials. In Proceedings of the $7^{\text {th }}$ International Symposium on Inorganic Phosphate Materials for Energy Storage, Argonne, Illinois, USA, Nov 2011. Belharouak, I. Pol, V. G., Eds. Ceram. Trans. 223, 2011, 195-202.

15. Bortun, A. I.; Bortun, L. N.; Clearfield, A. Ion Exchange Behavior of the $\mathrm{NH}_{4} \mathrm{TiOPO}_{4}$ Based Exchanger. Solv. Extract. Ion Exch., 1998, 16 669-681. https://doi.org/10.1080/07366299808934546

16. Inorganic Ion Exchange Materials. Clearfield, A., Ed. CRC Press, Boca Raton, Florida, USA, 1982

17. Eccles, H.; Bond, G.; Emmott, J. D. ADVANCED REPROCESSING THE POTENTIAL FOR CONTINUOUS CHROMATOGRAPHIC SEPARATIONS. J. Chromatog. Sep. Tech., 2017, 8, 348. http://doi.org/10.4172/2157-7064.1000348

18. Bond, G.; Eccles, H.; Kavi, P. C.; Holdsworth, A. F.; Rowbothan, D.; Mao, R.; Removal of Cesium from Simulated Spent Fuel Dissolver Liquor. J. Chromatog. Sep. Tech., 2019, 10, 1, 1000417. https://doi.org/10.4172/2157-7064.1000417

19. Holdsworth, A.F.; Eccles, H.; Rowbotham, D.; Bond, G.; Kavi, P.C.; Edge, R. The Effect of Gamma Irradiation on the Ion Exchange Properties of Caesium-Selective Ammonium PhosphomolybdatePolyacrylonitrile (AMP-PAN) Composites under Spent Fuel Recycling Conditions. Separations, 2019, 6, 23. https://doi.org/10.3390/separations6020023

20. Holdsworth, A.F.; Eccles, H.; Rowbotham, D.; Brookfield, A.; Collison, D.; Bond, G.; Kavi, P.C.; Edge, R. The Effect of Gamma Irradiation on the Physiochemical Properties of Caesium-Selective Ammonium Phosphomolybdate-Polyacrylonitrile (AMP-PAN) Composites. Clean Technol., 2019, 1, 294-310. https://doi.org/10.3390/cleantechnol1010020
21. Bond, G.; Eccles, H.; Emmott, J. D. Separation of Cations from Nitric Acid Solutions Using Commercially Available Ion Exchange Resins. J. Chem. Eng. Proc. Tech., 2019, 10, 1, 939. https://doi.org/0.4172/2157-7048.100039

22. Holdsworth, A.F.; Eccles, H.; Halman, A.M.; Mao, R.; Bond, G. LowTemperature Continuous Flow Synthesis of Metal Ammonium Phosphates. Sci Rep, 2018, 8, 13547. https://doi.org/10.1038/s41598-018-31694-x

23. Piccirilllo, C.; et al. Aerosol assisted chemical vapour deposition of hydroxyapatite-embedded titanium dioxide composite thin films. J. Photochem. Photobiol. A: Chem., 2017, 332, 45-53. https://doi.org/10.1016/j.jphotochem.2016.08.010

24. Cotton, F. A.; Wilkinson, G. Advanced Inorganic Chemistry, $5^{\text {th }}$ ed. Wiley: New York, USA, 1988.

25. Takeno, N. Atlas of Eh-pH Diagrams: Intercomparison of Thermodynamic Databases, Geological Survey of Japan Report 419, 2005.

26. Sherry, H. S.; Walton, H. F. The Ion-Exchange Properties of Zeolites. II. Ion Exchange in the Synthetic Zeolite Linde 4-A. J. Phys. Chem., 1967, 71, 5, 1457-1465. https://doi.org/10.1021/j100864a042

27. Coetzee, C. J.; Van Wyk, A. J. Cation Exchange Studies on Ammonium-12-Molybdophosphate - II. J. Inorg. Nucl. Chem., 1971, 33, 1501-1508. https://doi.org/10.1016/00221902(71)80447-5

28. Ganzerli Valentini, M. T.; Maxia, V.; Rollier, M. A.; Barbaro Forleo, M. Behaviour of Uranyl Ion in Nitric Acid Solutions with Ammonium Molybdophosphate. J. Inorg. Nucl. Chem., 1970, 32, 671-679. https://doi.org/10.1016/0022-1902(70)80277-9

29. Ganzerli Valentini, M. T.; Maxia, V.; Meloni, S.; Barbaro Forleo, M.; Rollier, M. A. Separation of Thorium, Uranium, and Neptunium on Chromatographic Columns Loaded with Ammonium 12 Molybdophosphate. J. Radioanal. Chem., 1972, 11, 179-187. https://doi.org/10.1007/BF02514021

30. Sarkar, A. K. Hydration/dehydration characteristics of struvite and dittmarite pertaining to magnesium ammonium phosphate cement systems. J. Mater. Sci., 26, 1991, 2514-2518. https://doi.org/10.1007/BF01130204

31. Frost, R. L.; Weier, M. L.; Erickson, K. L. Thermal decomposition of struvite. J. Thermal Anal. Calorim., 2004, 76, 3, 1025-1033. https://doi.org/10.1023/B:JTAN.0000032287.08535.b3

32. Griffith, C. S.; Luca, V.; Sebesta, F.; Yee, P. Separation of Cesium and Strontium from Acidic Radioactive Waste Simulants Using a Microporous Tungstate/Polyacrylonitrile (PAN) Composite Adsorbent. Sep. Sci. Tech., 2005, 40, 9, 1781-1796. https://doi.org/10.1081/SS-200064561

\section{6: Acknowledgements}

This research was funded by the EPSRC; grant number EP/M026485/1. We would like to thank Drs R. Mao and A. M. Halman, Mrs T. Garcia-Sorribes, Mr P. Bentley, and Mr J. C. Donelly for technical and experimental assistance, Dr M. D. Ogden for his valued discussions, and to Prof $K$. Singh and her group for kind provision of analytical equipment. The authors declare no conflicts of interest. The funders had no role in the design of the study; the collection, analyses, or interpretation of data; the writing of the manuscript, or in the decision to publish the results. 